\title{
ESTUDOS BASEADOS NA PRÁTICA: POSSIBILIDADES METODOLÓGICAS PARA PESQUISAS EM ESTUDOS ORGANIZACIONAIS
}

\author{
Practice-Based Studies: methodological possibilities for \\ research on organization studies
}

Ricardo Pimentel*

Eloy Eros da Silva Nogueira**

\section{RESUMO}

No artigo discutimos uma proposta metodológica para estudos baseados na prática (EBP), visando ampliar as possibilidades teóricas e empíricas no campo dos estudos organizacionais. A partir do conceito de prática de Schatzki, discutimos sua base fenomenológica, bem como a possibilidade de integrar as diversas dimensões da prática expressas na diversidade de abordagens, identificadas na revisão de seis edições especiais de periódicos europeus sobre o tema. Nossa proposição é a adoção de uma imersão baseada na fenomenologia como método e na etnografia como estratégia de pesquisa, que permita a ampliação do envolvimento do pesquisador na prática estudada. Nós propomos, ainda, a adoção de técnicas de pesquisa que ampliem a capacidade de descrição, representação e compreensão dessa prática, especialmente em estudos de fenômenos sociais como poder, agência, aprendizagem organizacional entre outros.

Palavras-chave: Teoria da prática. Fenomenologia. Etnografia. Imersão fenomenológica.

\begin{abstract}
In this paper we discuss a methodological proposal for practice-based studies (PBS), aiming to expand the theoretical and empirical possibilities in the field of organization studies. Based on Schatzki's concept of practice, we discuss its phenomenological basis, as well as the possibility of integrating the various dimensions of practice expressed in the diversity of approaches identified in the review of six special issues of European journals on the subject. As a method, we propose a phenomenology-based immersion, and ethnography as a research strategy, that allows for the expansion of the researcher's involvement in the practice being studied. We also offer for consideration the adoption of research techniques that enhance the ability to describe, represent and understand this practice, especially in studies of social phenomena such as power, agency, organizational learning, among others.
\end{abstract}

Keywords: Practice theory. Phenomenology. Ethnography. Phenomenological immersion.

\footnotetext{
* Professor do Programa de Mestrado Profissional em Governança e Sustentabilidade do ISAE - PR, Doutor em Administração pela Universidade Positivo com estágio doutoral na Aarhus University - Dinamarca. E-mail: pimentel.ric@uol.com.br.

** Professor do Programa de Pós-graduação em Administração da Universidade Positivo (PMDA/UP), Doutor em Administração pela EAESP - Fundação Getúlio Vargas. E-mail: procedimentosqualitativosup@gmail.com.
} 


\section{INTRODUÇÃO}

O objetivo desse artigo é contribuir com a discussão de possibilidades metodológicas para estudos organizacionais dentro da abordagem dos Estudos Baseados na Prática - EBP (practice-based studies - PBS), e vem se juntar ao empenho de outros estudos com vistas a ampliar as possibilidades teóricas e empíricas. Essa discussão se justifica tendo em vista o crescimento de estudos com essa abordagem na produção acadêmica brasileira e, especialmente, a discussão acerca da diversidade de perspectivas que caracteriza os EBP (BISPO, 2013; BISPO; GODOY, 2014; LEMOS; ALCADIPANI, 2015; BISPO, 2015a; 2015b).

Dentre esses esforços destacamos o de Bispo (2013), que apresenta uma revisão histórica do desenvolvimento dos EBP a partir da formação do European Group on Organization Studies (Egos), mostrando como desde o início estava presente a questão da diversidade de abordagens teóricas. 0 autor identifica quatro tradições: cultural interpretativa, das comunidades de prática, da atividade cultural e histórica, e da teoria ator-rede. Em trabalho posterior, Bispo (2015a) além de trazer à cena também a teoria de Schatzki, avança na discussão dos procedimentos metodológicos decorrentes dessa abordagem, focalizando as possibilidades da praxeologia, do shadowing e da entrevista com o sósia. Destacamos também o trabalho de Lemos e Alcadipani (2015, p. 92), que apresenta as contribuições de Schatzki e suas consequências para os estudos organizacionais, como a necessidade de "desnaturalizar aquilo que as análises organizacionais tradicionais assumem como não problemático, o status do fenômeno organizacional".

Aqui apresentamos uma revisão bibliográfica junto a seis edições especiais de periódicos europeus dedicados ao tema, visando compreender o processo de construção dos EBP no cenário acadêmico europeu e, a partir daí, levantar algumas possibilidades metodológicas que possam instigar ainda mais os pesquisadores na construção de estudos voltados para a realidade organizacional brasileira.

Na sequência o artigo discute os conceitos centrais da teoria de Schatzki e suas implicações epistêmicas e metodológicas, explorando as possibilidades a partir das bases fenomenológicas originárias dessa teoria.

Nossa reflexão segue as sugestões de Nicolini (2014) de que é chegada a hora de irmos além do trabalho de construção da teoria da prática, superando os exercícios semânticos e as elaborações ontológicas abstratas, para nos aproximarmos dos fenômenos sociais com a expectativa que eles emerjam e transpirem dos dizeres e fazeres interconectados e situados.

\section{ESTUDOS BASEADOS NA PRÁTICA:}

UMA TRAJETÓRIA DE CONSTRUÇÃO ONTOLÓGICA E EPISTEMOLÓGICA

Um EBP se caracteriza pelo fato de tomar a prática como unidade de análise e se originou nas atividades de pesquisa acadêmica desenvolvidas por um conjunto de pesquisadores europeus, que nos últimos anos vem se difundindo no Brasil. A predominância em 
congressos e eventos mostra a força com que essa produção vem crescendo, e já aparecendo também em periódicos da área, inclusive em âmbito internacional, o que reforça a necessidade das discussões teórico-metodológicas (TURETA; ALCADIPANI, 2009; CASSANDRE; CANOPF; APPIO; BULGACOV, 2010; QUEROLS; JACKSON FILHO; CASSANDRE, 2011; TURETA, 2011; AMÉRICO; TAKAHASHI, 2014; SOARES; BISPO, 2014; FARIA; LEITE-DA-SILVA, 2015; JULIO; BIANCO, 2015; JULIO; TURETA, 2015; JULIO, 2015; LÔBO, 2015; PIMENTEL; NOGUEIRA, 2015; POUBEL; JUNQUILHO, 2015; SILVEIRA; DOIN, 2015; BISPO, 2016; IPIRANGA; LOPES; SOUZA, 2016).

Mais do que a construção de um arcabouço teórico-metodológico único, o termo EBP expressa um conjunto de esforços em pesquisas baseadas em teorias diversas, e que requerem também metodologias diversas. Apesar dessa diversidade há pontos comuns essenciais, dentre eles a busca pela superação dos dualismos tais como sujeito-objeto, mente-corpo, micro-macro, natureza-cultura, estrutura-agência, e inclusive, alguns dualismos que emergiram do próprio desenvolvimento dos EBP como hábito-ação ou rotina-agência (GHERARDI, 2009a, 2009b).

A proposição da prática como unidade de análise traz algumas consequências, das quais destacamos: (1) como unidade fundamental da constituição social, a prática não pode ser vista meramente por meio de relações entre propriedades externas de elementos que se relacionam entre si; (2) no estudo da prática deve-se evitar uma perspectiva epifenomênica, como se ela fosse apenas um contexto no qual os fenômenos ocorrem. A constituição e a manutenção de uma prática são também a constituição e manutenção dos elementos sociais que por vezes focalizamos nos estudos organizacionais, tais como relações de poder, aprendizagem, mudança, entre outros; e, por fim, (3) deve-se ter um cuidado especial com o uso do termo no singular e no plural. Muitos trabalhos utilizam termos como "teoria das práticas", "abordagem das práticas", entre outros. Sem querer investir em preciosismos, é preciso atentar para o fato que existem teorias e abordagens da prática como unidade de análise, mesmo que em muitos momentos estejamos estudando diversas práticas e suas conexões.

A seleção dos periódicos europeus dedicados ao tema permite uma visão sobre o desenvolvimento dos EBP, a diversidade de temas e abordagens, e de que maneira alguns elementos comuns vêm se estabelecendo. Esses elementos servem para aglutinar o empenho dos pesquisadores, e destacar as particularidades das abordagens que valorizam aspectos diferenciados do fenômeno, e desenvolver metodologias para dar conta dessa diversidade - etnometodologia, pragmatismo, teoria da atividade, teoria ator-rede, as tradições filosóficas fenomenológicas e existenciais, a análise do discurso, entre outras. Com o objetivo de destacar como esses pontos comuns foram trabalhados ao longo do tempo e como se consolidaram, apresentam-se alguns estudos publicados nos referidos periódicos.

Muitas das questões desenvolvidas ao longo de inúmeros trabalhos, que as edições especiais apresentadas servem como exemplos, mas não as esgotam, são desenvolvimentos de determinados aspectos da prática. Sendo assim, a discussão focada especificamente nos elementos que constituem o conceito de prática, especialmente em seus aspectos ontológicos, realizada na edição especial da Human Affairs de 2007, marcaram de forma indelével o que aconteceu posteriormente. 
Schatzki (2007) destaca a importância da compreensão do nexo entre atividade e sociabilidade e dos elementos que os suportam, tais como o caráter da atividade humana, a natureza do sentido e da linguagem, a natureza da comunicação e da aprendizagem, entre outros. Porém, na mesma medida em que os desafios são variados, também é a noção de prática; a chamada teoria da prática é apontada pelo autor como uma tendência geral do pensamento social contemporâneo que estuda a vida humana por meio desta noção, ou por referência.

Já no ano seguinte, na edição do European Business Review, Brownlie, Hewer, Wagner e Svensson (2008) apontam para a necessidade de mudanças e de certa radicalização nas formas de abordar e compreender o conhecimento, e especialmente, uma preocupação metodológica que se expressa na relação com aqueles que devem estar representados nessas pesquisas, ou que possam se utilizar do conhecimento produzido nelas: os profissionais, os estudantes e os pesquisadores acadêmicos.

Isso também pode ser notado nas discussões realizadas por Gherardi (2009a) na edição especial do Management Learning, das quais se destacam dois aspectos importantes: o primeiro é a explicitação da polissemia do conceito e o uso da metáfora da prática como uma "lente". Mesmo considerando que essa metáfora possui limitações à medida que mantém o pesquisador como um outsider, seu uso foi importante para a construção da ideia de um olhar "de fora" e um olhar "de dentro" da prática, instigando os pesquisadores a buscarem soluções metodológicas que ampliassem a visão "de dentro".

O segundo aspecto importante discutido pela autora é a apresentação das principais contribuições do conceito de prática para os EBP em organizações, alguns dos quais podem ser considerados tentativas de superar os desafios apontados acima, bem como estão presentes nas discussões que se seguiram e passaram a ser norteadores de muitos trabalhos: (1) a organização passa a ser vista como uma teia de práticas interconectadas e sustentadas por um conhecimento dinâmico e processual (knowing) que se renova e se transforma ao ser praticado; (2) o conhecimento visto dessa forma é um fenômeno situado, negociado, emergente e incorporado; (3) a dimensão material dessas práticas que formam a organização é entendida em relação íntima com os seres humanos e com papel importante na noção de agência; (4) uma metodologia para análise que valoriza o papel do conhecimento no trabalho e o entende como knowing-in-practice; e, por fim, (5) o desenvolvimento de um novo léxico que produza novas expressões e conceitos, que sejam capazes de expressar as nuances que diferenciam essa abordagem, e contribuam com a renovação dos estudos organizacionais.

Além do artigo de Gherardi, dentre os publicados nessa edição, selecionamos e destacamos três deles para o propósito deste artigo: (1) o artigo de Nicolini (2009a) que discute a entrevista com o sósia (interview to the double - ITTD) como recurso para a representação da prática; (2) o artigo de Bjørkeng, Clegg e Pitsis (2009) que mostra a importância do uso da etnografia na apreensão do processo de construção e reconstrução de uma prática; e, por fim, o artigo de Geiger (2009) que ao incorporar a noção habermasiana de life-world, enfatiza a possibilidade de elaboração de uma visão crítica da realidade a partir do olhar sobre a prática.

Como uma construção conjunta, mais duas edições especiais de 2009 trabalham temas ligados aos EBP. Na primeira, Organization Studies se volta para um balanço dos 
EBP com especial ênfase para a discussão dos diferentes conceitos de prática. Miettinen, Samra-Fredericks e Yanow (2009) fazem uma profícua discussão tendo como referência o termo practice turn que os autores renomeiam para re-turn to practice. Ao mostrar as diversas raízes do termo prática, e consequentemente a multiplicidade de resgates dessas tradições bem como novas perspectivas, o que o editorial produz de mais interessante é uma síntese dos temas comuns às diversas abordagens: a natureza incorporada da prática; a crítica à noção de conhecimento como representações verbais ou textuais do mundo; a valorização do modo de agir e usar artefatos na constituição do conhecimento; o significado dos objetos materiais e artefatos para a prática.

É dessa edição o importante artigo de Nicolini (2009b) em que ele inicia a construção de alternativas metodológicas capazes de dar conta da natureza do fenômeno da prática. $\mathrm{O}$ autor propõe que se utilizem dois movimentos num EBP. $\mathrm{O}$ primeiro ele chamou de zooming in, e se caracteriza pelo mergulho na prática quando ela está ocorrendo. Só o envolvimento profundo permite identificar e analisar os elementos constituintes, que podem ser acessados pela dimensão discursiva e pela dimensão material, expressos nos "dizeres e fazeres" da prática estudada.

O segundo movimento é denominado pelo autor como zooming out e consiste em ampliar o raio de investigação para encontrar os nexos que ligam a prática estudada a outras práticas, com o objetivo de entender a organização. Ao se estabelecerem as conexões da prática no aqui-agora com outras práticas que persistem no tempo e no espaço formando uma textura de dependências e referências, é possível ampliar a capacidade de entender a vida organizacional no que ela tem de perene e de transitório.

A segunda é a edição especial do The Learning Organization, de 2009, que faz um balanço dos EBP especificamente no campo do Conhecimento e Aprendizagem Organizacional, e pode ser colocada lado a lado com a edição especial da European Business Review lançada no ano anterior. Em ambas é possível destacar a preocupação com o conhecimento, a aprendizagem e a ação. No editorial Gherardi (2009b) empreende uma análise da importância de um novo olhar sobre os conceitos de organização e de conhecimento, e de que maneira as abordagens baseadas na prática podem contribuir com a superação desse desafio. De certa forma as discussões nesse editorial, e em artigos publicados nessa edição, avançam questões colocadas na edição do ano anterior citada acima, na qual é discutido o gap entre teoria e prática nos estudos organizacionais da Administração.

Mais à frente, no editorial da edição especial do Journal of Organizational Change Management, Eikeland e Nicolini (2011) se propõem a realizar uma consolidação do campo de estudo. Dedicada à discussão da action research como caminho para a mudança e o desenvolvimento organizacional, tanto o referido editorial quanto a edição como um todo, são uma contribuição importante para se entender como o campo se desenvolvera até então, e seu estado da arte.

Em primeiro lugar conseguem estabelecer uma diferenciação entre as diversas abordagens da prática, propondo uma descrição do campo em que põe em evidência sua consolidação e autonomia e por outro lado a abrangência e a capacidade explicativa das diferentes abordagens. O Quadro 1 mostra que, a partir da perspectiva (de fora e de cima; e de dentro e de baixo) e da direção do interesse (prático ou teórico), os autores estabelecem quadrantes que vão de estudos mais tradicionais, que mesmo focalizando a prática ainda 
o fazem com sentido operacional exacerbado, passando por uma perspectiva teórica que visa testar métodos e teorias, até o que eles consideram a forma mais avançada na qual a capacidade crítica está em produzir teorias a partir da prática. Essa capacidade crítica imanente viria do fato de que a produção de conhecimento teórico se dá a partir da atividade e da explicitação da sua "gramática", abrindo novas possibilidades de ação (EIKELAND; NICOLINI, 2011).

A constatação feita pelos autores de que as pesquisas nessa perspectiva ainda são escassas, é reforçada por Sandberg e Tsoukas (2011) e por Dall'Alba e Sandberg (2014), ao mostrarem que muitos EPB ainda mantêm insolúvel a questão da separação sujeito-objeto que impera na racionalidade científica moderna. Dentro do propósito de descrever um quadro sumário do desenvolvimento dos EPB, vale ressaltar que essa crítica é dirigida ao próprio campo.

Quadro 1 - Modos de focalizar as práticas nas ciências sociais

\begin{tabular}{|c|c|c|c|}
\hline \multirow{2}{*}{\multicolumn{2}{|c|}{$\begin{array}{l}\text { Modos de focalizar as práticas nas } \\
\text { ciências sociais }\end{array}$}} & \multicolumn{2}{|c|}{ Direção do interesse } \\
\hline & & $\begin{array}{c}\text { Amplamente prática (Objetivo: } \\
\text { desencadear a } \\
\text { ação, produzindo mudança e } \\
\text { melhoria) }\end{array}$ & $\begin{array}{c}\text { Amplamente teórica (Objetivo: ampliar o } \\
\text { conhecimento, produzindo compreensão } \\
\text { ou explicações) }\end{array}$ \\
\hline \multirow{2}{*}{$\begin{array}{l}\text { Ponto de } \\
\text { Partida }\end{array}$} & $\begin{array}{l}\text { Do lado de fora e acima: } \\
\text { A partir de uma posição } \\
\text { de espectador de fora da } \\
\text { ação de interesse } \\
\end{array}$ & $\begin{array}{l}\text { Desenvolver técnicas } \\
\text { especializadas / } \\
\text { pesquisa aplicada }\end{array}$ & $\begin{array}{c}\text { Ciência normal (abordagens explicativas e } \\
\text { interpretativas) (theoresis) }\end{array}$ \\
\hline & $\begin{array}{l}\text { De dentro e baixo: De } \\
\text { uma posição imersa na } \\
\text { ação de interesse }\end{array}$ & $\begin{array}{l}\text { Participação com foco na melhoria } \\
\text { deliberada das práticas (phronêsis) }\end{array}$ & $\begin{array}{l}\text { Provocar o diálogo crítico - crítica } \\
\text { imanente (theoria) }\end{array}$ \\
\hline
\end{tabular}

Fonte: Eikeland, O.; Nicolini, D., 2011.

Dois estudos contidos na referida edição são exemplos de direcionamento aos estudos mais críticos e com maior potencial de criar teorias, e que contribuem com a construção de métodos diversificados de coleta e análise de dados. 0 primeiro deles é a pesquisa realizada por Kostulski (2011) que a partir da Teoria da Atividade de Vigotski e da Clínica da Atividade de Ives Clot $(1999 ; 2008)$ mostra como é possível um processo de reflexão na atividade profissional, que leva a patamares mais desenvolvidos de entendimento da realidade. No caso específico, um lapsus linguae provoca um processo de investigação de promotores públicos, não em relação a réus ou suspeitos, mas em relação à própria atividade desenvolvida por eles. Essa reflexão só pôde ocorrer à medida que um método de pesquisa intervencionista foi aplicado a esse grupo de profissionais.

O segundo exemplo é o estudo de ledema e Carrol (2011), que focado nas práticas dos gestores de um hospital, utilizam vídeo-etnografia e abordagem multidisciplinar para promover o que eles chamam de vídeo-reflexividade e proporcionar uma visão da atividade que permite uma maior flexibilidade frente ao ambiente complexo de um serviço de cuidados de saúde. Em ambos os estudos chama a atenção a busca por metodologias e 
por estratégias de pesquisa que permitam observar dimensões da prática, que não seriam alcançados por meio de "ferramentas tradicionais".

A revisão das edições apresentadas nesse artigo, e sintetizadas no Quadro 2, bem como outros trabalhos importantes (SCHATZKI, 2012; NICOLINI, 2013; GHERARDI, 2012) nos permite destacar três dimensões que foram trabalhadas ao longo do tempo de forma concomitante, mas com a predominância de uma delas em diferentes fases: (1) a construção de um léxico capaz de dar conta da construção filosófica, ontológica e epistemológica do conceito de prática, (2) a construção de arcabouços teóricos que suportem a prática como unidade de análise, e por fim, (3) a construção de metodologias.

Quadro 2 - Síntese da revisão dos periódicos selecionados

\begin{tabular}{|c|c|c|c|}
\hline Periódico & $\begin{array}{l}\text { Tema principal da } \\
\text { edição especial }\end{array}$ & Principal(is) contribuição(ões) & Destaques da edição \\
\hline Human Affairs (2007) & Conceito de prática & Construção do léxico e delimitação do campo & $\begin{array}{l}\text { Dreyfuss (2007); Schatzki } \\
\text { (2007); Simonsen (2007); } \\
\text { Turner (2007) }\end{array}$ \\
\hline $\begin{array}{l}\text { European Business } \\
\text { Review (2008) }\end{array}$ & $\begin{array}{l}\text { Radicalização da } \\
\text { noção de } \\
\text { conhecimento }\end{array}$ & $\begin{array}{c}\text { Construção do léxico com ênfase na construção } \\
\text { metodológica }\end{array}$ & $\begin{array}{l}\text { Brownlie et. al. (2008); Fendt } \\
\text { et. al. (2008); Holbrook } \\
(2008)\end{array}$ \\
\hline $\begin{array}{l}\text { Management Learning } \\
\text { (2009) }\end{array}$ & $\begin{array}{c}\text { Explicitação e } \\
\text { discussão da } \\
\text { polissemia do } \\
\text { conceito de prática }\end{array}$ & Prática como "lente" & $\begin{array}{l}\text { Bjørkeng, Clegg e Pitsis (2009) } \\
\text {; Gherardi (2009a); Nicolini } \\
\text { (2009a) }\end{array}$ \\
\hline $\begin{array}{l}\text { Organization Studies } \\
\qquad \text { (2009) }\end{array}$ & $\begin{array}{c}\text { Rediscussão dos } \\
\text { conceitos de práticas }\end{array}$ & $\begin{array}{c}\text { Foco na diversidade de abordagens e síntese } \\
\text { dos pricipais temas: a natureza incorporada da } \\
\text { prática; a crítica à noção de conhecimento como } \\
\text { representações verbais ou textuais do mundo; } \\
\text { a valorização do modo de agir e usar artefatos } \\
\text { na constituição do conhecimento; o significado } \\
\text { dos objetos materiais e artefatos para a prática. }\end{array}$ & $\begin{array}{l}\text { Miettinen, Samra-Fredericks e } \\
\text { Yanow (2009); Nicolini (2009b) }\end{array}$ \\
\hline $\begin{array}{l}\text { The Learning } \\
\text { Organization (2009) }\end{array}$ & \begin{tabular}{|} 
Conhecimento e \\
aprendizagem \\
organizacional: \\
revisão dos conceitos \\
de organização e de \\
conhecimento
\end{tabular} & $\begin{array}{c}\text { Discussão do gap entre teoria e prática nos } \\
\text { Estudos Organizacionais }\end{array}$ & $\begin{array}{l}\text { Gherardi (2009b); Labatut et. } \\
\text { al. (2009); Svabo (2009); }\end{array}$ \\
\hline $\begin{array}{l}\text { Journal of } \\
\text { Organizational Change } \\
\text { Management (2011) }\end{array}$ & $\begin{array}{l}\text { Esforço de } \\
\text { consolidação do } \\
\text { campo }\end{array}$ & $\begin{array}{l}\text { Diferenciação e tipificação das abordagens (ver } \\
\text { Quadro 1) }\end{array}$ & $\begin{array}{l}\text { Eikeland \& Nicolini (2011); } \\
\text { ledema \& Carrol (2011); } \\
\text { Kostulski (2011); Sandberg \& } \\
\text { Tsoukas (2011). }\end{array}$ \\
\hline
\end{tabular}

Fonte: Elaborado pelos autores a partir dos periódicos selecionados.

Vistas em perspectiva, as edições especiais de periódicos europeus selecionados mostram que muito dos desafios da abordagem da prática têm sido enfrentados pelos pensadores e pesquisadores do campo. Acreditamos que novos desafios se colocam, tais como aqueles já citados anteriormente (NICOLINI, 2014). Com o objetivo de contribuir com esse refinamento, apresenta-se a seguir uma discussão sobre alguns dos elementos constituintes da prática, e de que modo se relacionam e contribuem com o trabalho empírico. 


\section{UM CONCEITO SINGULAR DA PRÁTICA COMO UNIDADE DE ANÁLISE: UMA DISCUSSÃO A PARTIR DA PERSPECTIVA DA TEORIA DE SCHATZKI}

Estudar a prática é focalizar as ligações entre os fazeres e dizeres como ações básicas, bem como os objetos materiais que dão suporte a essas ações. Essas ações básicas se ligam a outras ações do próprio sujeito e de outros, com a utilização de uma gama maior de objetos materiais, num nível cada vez maior de complexidade, formando as atividades. Essas atividades são humanas e coletivas, mas não coincidem necessariamente com a prática (SCHATZKI, 2012).

Nesse sentido, a prática é constituída por todas as ações, atividades e objetos materiais contidos nessas hierarquias teleológicas que, por envolverem projetos humanos e coletivos, são também estados de existência. Essa noção de prática está baseada na tradição filosófica fenomenológica, especialmente em Heidegger (2010), na qual a inteligibilidade tem papel preponderante, ao considerar que as relações humanas e sociais são parte de um processo contínuo no qual as pessoas normalmente fazem e dizem aquilo que se constitui com algum sentido. Como parte desse processo contínuo, o sentido e os indivíduos que os definem não podem ser vistos como unidades básicas de análise por serem elementos situados e contextuais: só a prática ocorrendo em tempo real pode ajudar a revelar essa inteligibilidade, e aquilo que permite compreender a conduta humana e a ordem social (NICOLINI, 2013).

A inteligibilidade torna-se um elemento importante na constituição da prática, considerando que esta estruturação das ações/atividades/objetos é também o elemento que liga uma prática a outras práticas, formando uma ordem social local. Schatzki $(1996 ; 2012)$ destaca que essa concepção de prática como atividades coletivamente organizadas, leva em conta a inteligibilidade por considerar que a base da atividade humana são habilidades corporais não proposicionais, ou seja, que não seguem um plano racional de decisões prévias. Como atividades organizadas, também não são determinadas unicamente por elementos normativos como regras, habitus ou cultura: o que prevalece é o que o autor chama de ações inteligíveis.

Reconhecer o fato de que a ordem social se insere no campo da prática, é reconhecer que é nela que os arranjos entre pessoas, artefatos, objetos, organismos, e suas relações e sentidos são estabelecidos. Assim, tem-se aqui um aspecto operacional dessa perspectiva: à medida que é possível conhecer os arranjos de práticas e os mecanismos que os constituem, torna-se possível conhecer os fenômenos sociais mais amplos que emanam dessas práticas tais como as organizações, bem como aqueles que permeiam a vida social de forma mais difusa, tais como a aprendizagem.

Lemos e Alcadipani (2015) enfatizam o aspecto contextual das práticas ao destacarem os arranjos sociomateriais como seu cenário. Embora Schatzki (2002) utilize o termo cenário, este não deve ser visto como uma separação entre os referidos arranjos e a prática. Em trabalhos mais recentes (SCHATZKI, 2012) o autor enfatiza o entrelaçamento entre eles, bem como o entrelaçamento entre as diversas práticas. Nesse sentido, os arranjos sociomateriais são eles próprios constituintes de uma prática, bem como o produto desta ou de outras práticas. 
Mais do que ações ou atividades individuais isoladas carregadas de intencionalidade, a prática é ao mesmo tempo o conteúdo, o processo e o resultado das atividades humanas, cuja natureza é intrinsecamente coletiva: ações, desempenho e trabalho só fazem sentido à medida que estabelecem uma ligação eu-outro(s) e permitem a sobrevivência coletiva.

O maior desafio talvez seja como capturar, representar, interpretar e compreender, a inteligibilidade da prática. Esse desafio se dá por alguns aspectos que se destacam: (1) não há uma inteligibilidade, pois se trata de uma construção constante entre os praticantes e no campo da interconexão entre diferentes práticas; (2) não é algo que se possa delimitar e descrever de forma totalmente objetiva; (3) é situada, e só faz sentido se compreendida no seio do arranjo de práticas a que ela se refere; (4) não pode ser totalmente expressa pela linguagem, e precisa ser buscada também na corporeidade, nos arranjos sociomateriais e nos elementos éticos e estéticos, como apontado por Gherardi (2009c). Uma prática pode ser acessada também ao se focalizar o processo de negociação coletiva sobre o que os praticantes pensam ser correto e adequado fazer. Esse sentido intersubjetivamente criado permite a realização de uma prática inúmeras vezes, na qual não somente a repetição pode revelar elementos dela, mas também os seus desarranjos e variações.

\section{METODOLOGIAS PARA EBP:}

INVESTIGANDO CONDIÇÕES DE COMBINAÇÕES E INTEGRAÇÃO DE MÉTODOS E RECURSOS, E EXPLORANDO A BASE FENOMENOLÓGICA DA TEORIA

A delimitação de uma pesquisa tem papel fundamental em todo o processo de investigação da realidade. Conforme aponta Grix (2002), há uma relação lógica entre ontologia, epistemologia, metodologia, métodos e fontes de dados. Mais do que uma mera sequência, essa relação aponta para o fato de que a construção de uma pesquisa requer uma coerência interna entre esses elementos. Essa coerência não deve servir a um enrijecimento da pesquisa, mas ao contrário, deve permitir as bases seguras sobre as quais o pesquisador poderá se lançar a novas descobertas e estar aberto a novas formas de abordagem da realidade.

Inspirado por essas ideias, o presente artigo busca contribuir com o trabalho de construir metodologias de pesquisa que permitam a ampliação da capacidade de apreensão e de compreensão das dimensões individuais e coletivas dos fenômenos humanos e sociais. Outro aspecto que está presente nas discussões empreendidas aqui é a ideia de que os EBP invistam muito mais na diversidade do que na busca por unanimidades teóricas e metodológicas. Nesse sentido, seguimos as orientações de Nicolini (2013) no sentido de construção de um "kit de ferramentas" como fonte de alternativas metodológicas capazes de dar conta da natureza do fenômeno da prática.

O primeiro aspecto que deve ser tratado é o fato de que, se tratadas de forma isolada, as diferentes estratégias e técnicas de pesquisa não possuem a mesma força do que concebidas como parte da construção teórico-metodológica, ou "kit de ferramentas" como tratado acima. 0 artigo de Bispo (2015a) contribuiu com a discussão metodológica por inicialmente colocá-la em pauta de forma explícita, mas deixou em aberto as discussões 
sobre a relação entre o referencial teórico, a metodologia, as estratégias e as técnicas de pesquisa. Nosso intuito a partir daqui é propor uma discussão que possa contribuir para uma visão mais ampla e integrada.

Nossa proposição é a adoção de uma imersão fenomenológica, baseada na fenomenologia como método e na etnografia como estratégia de pesquisa. Antes de apresentar as características dessa proposta, e os argumentos defesa da mesma, cabe uma discussão prévia sobre o uso da etnografia como estratégia em um EBP.

Os EBP têm se revelado um laboratório para as reflexões e explorações de questões ontológicas, epistêmicas e metodológicas. Como esperamos ter deixado claro na revisão bibliográfica e teórica, os avanços teóricos algumas vezes confrontam pressupostos teoréticos, e acusam as limitações postas pela mediação dos métodos, e vice-versa. Os autores anteriormente citados revelam isso em seus trabalhos, e chegam mesmo a colocar o desenvolvimento de métodos como um objetivo primário a ser buscado. E este artigo procura se alinhar com esses propósitos e esforços.

Adotamos que a etnografia é um método, pertencente ao domínio das teorias metodológicas, e das formas e das estratégias de realizar a pesquisa científica, e que os EBP pertencem ao domínio das teorias do objeto, no caso a prática. Como alguns dos traços caracterizadores do método colocamos em destaque, conforme bem resumido por Ybema et. al. (2009): realização de trabalho de campo; contato em tempo real com o objeto de estudo; existência de dimensões não materiais, e muitas vezes não aparentes; atenção para com o contexto; multiplicidades de posições, situações, atores. E também por Angrosino (2008): baseado em pesquisa de campo; personalizado; com uso possível de várias técnicas; indutivo, dialógico e holístico.

A etnografia pode ser orientada para uma diversidade de objetos (comunidade, cultura, acontecimento, etc.) ou unidades de análise (fatos, valores, instituições, processos etc.). Ela também pode ter diferentes pressupostos teoréticos ou paradigmas (ex.: interpretativistas, construtivistas, construcionistas, críticos etc.), e cada uma delas poderá significar uma etnografia distinta das outras, apesar de serem todas etnografias.

A etnografia organizacional e a etnografia da vida cotidiana nas organizações têm suas peculiaridades quando comparadas com outros tipos de etnografias (BARLEY; KUNDA, 2001; BATE, 1997). Como resumidamente explicado neste artigo, os EBP desafiam as visões da organização e do cotidiano como estados ou quase objetos, mas, sim, como resultantes de práticas: a combinação inteligível de ações, artefatos (materiais e não materiais), símbolos, pessoas. Destacamos a posição de Nicolini (2009, p. 120):

Uma das implicações desse entendimento performativo das organizações é a renovação do foco sobre as práticas de trabalho na pesquisa organizacional... Esta virada requer estudar as práticas de trabalho e suas relações in situ - isto é etnograficamente. Somente através da imersão e estando lá é que alguém é capaz de apreciar, entender e traduzir a natureza situada, criativa, interpretativa e moral das práticas reais do organizar e da organização. Ao mesmo tempo, a aproximação etnográfica ajuda-nos a apreciar que as práticas de trabalho não ocorrem em um vácuo e que as vidas organizacionais das pessoas são moldadas tanto através das agências individuais, quanto das condições históricas. 
Sendo assim, a busca etnográfica é um tipo de abordagem da realidade que tem vida própria, pode e deve ser utilizada em diversos campos de conhecimento da realidade social, mas que em um EBP assume um papel estratégico específico: permitir o envolvimento do pesquisador com a(s) prática(s) estudada(s), de tal forma que o processo contínuo e recursivo de identificação e estranhamento oportunize a aproximação com a experiência vivida e que sua apreensão seja mais significativa do que em abordagens "não-êmicas".

A imersão proposta por nós tem por objetivo dar conta da multiplicidade e refletividade da vida humana. Por ser baseada em atividades processuais, relacionais e negociáveis, a intersubjetividade é um elemento fundamental na apreensão de fenômenos sociais vistos nessa perspectiva, garantindo-se, por outro lado, que não haja uma simbiose entre as experiências do pesquisador e as experiências dos sujeitos do fenômeno focalizado (PRUS, 1996; PATRIOTTA, 2003; MANIDIS, 2015).

Enfatizamos a dimensão fenomenológica dessa imersão em virtude de nossa abordagem basear-se numa teoria cuja ontologia está fortemente baseada nas noções heideggerianas de being-in-the-world e de breakdown, trazendo à tona, dentre outros, o tema da intencionalidade. Não se trata de retornar às discussões circunscritas às noções de mente/ação, e de relações entre indivíduos, mas de estudarmos os processos em que se situam o social e as ações, e a construção dos sujeitos e indivíduos. Não é demais recordar as reflexões de Schatzki a respeito:

It follows that interrelations among lives that transpire through life conditions also presuppose practices. Sociality, consequently, is not merely a hanging-together as established by and otherwise transpiring within practices. Sociality is essentially an interrelating of lives within practices (SCHATZKI, 1996, p. 180).

A socialidade é parte do processo de manutenção e reconstrução de uma prática na medida em que ela situa a elaboração dos objetivos e fins a que uma prática se propõe, e dos quais nem sempre os praticantes têm plena consciência no sentido racional do termo. Isso fica mais claro se considerarmos que essa intencionalidade é parte do "estar-no-mundo" e do entwinement, pois estamos constantemente entrelaçados com outros seres humanos e com objetos, num mundo sociomaterial específico, ou em uma específica prática sociomaterial. É outro tipo de racionalidade e de lógica, chamada por alguns de racionalidade prática ou lógica das práticas. Muitas vezes, é na ocorrência de um breakdown, quando uma prática não acontece da forma que deveria, ou não alcança os fins a que se propôs, é que os praticantes podem ter consciência dela (SANDBERG; TSOUKAS, 2011; DALL'ALBA; SANDBERG, 2014).

Uma imersão fenomenológica como a que propomos, permite a adoção de técnicas de pesquisa, que se coerentes com o referencial teórico e adequadas ao fenômeno estudado e seu contexto, ampliam a capacidade de descrição, representação e compreensão da(s) prática(s) focalizada(s) alcançando os processos já referidos de zooming in e zooming out (NICOLINI, 2009a).

A ideia é que a imersão fenomenológica, suportada por uma perspectiva de prática não representacional e não proposicional, dê liberdade e segurança ao pesquisador 
para construir alternativas metodológicas prévias à ida ao campo, e que ao mesmo tempo garantam o espaço e a oportunidade para a emergência de novas alternativas que sejam demandadas pela condução do campo, e pelos elementos novos que emergirem dele. Se conhecer o processo de construção da inteligibilidade de uma prática é um elemento fundamental para se conhecer essa prática, a própria prática da pesquisa deve oferecer um meio fértil para a construção de sua própria inteligibilidade: é nesse processo recursivo que a profundidade analítica pode florescer.

Com base nos aspectos discutidos acima, apresentar alternativas metodológicas não pode ser uma mera lista de possibilidades, mas uma fonte de opções que o pesquisador tenha em mãos para poder lidar com aquilo que emerge no trabalho de campo, sem perder de vista seus referenciais filosóficos e teóricos, o problema e os objetivos da pesquisa, garantindo o rigor em detrimento da rigidez (BISPO, 2015a).

Em linhas gerais, é aconselhável que os métodos e técnicas utilizados privilegiem as perspectivas "êmicas", ou seja, que priorizam o acesso à vida, aos pensamentos, sentimentos, entendimentos e significados produzidos pelos sujeitos praticantes. Como já destacado por outros autores, a entrevista com o sósia é uma técnica importante. Baseada na pergunta "Se eu fosse seu sósia, e amanhã viesse trabalhar no seu lugar, o que eu deveria fazer para que ninguém percebesse a troca?", ela permite transpor a barreira da racionalidade e da repressão inconsciente; dá visibilidade ao trabalho passado por meio de uma descrição do futuro; permite acessar ao modo como o entrevistado ordena o mundo coletivo a partir de uma perspectiva individual; revela ambiguidades; contribui para acessar a normatividade da prática; e, por fim, permite apreender as interconexões entre diferentes práticas como meio de acessar e representar a organização social (NICOLINI, 2009; GHERARDI, 2012; BISPO, 2015a).

Além do fato de que seu uso deva ser combinado com outras técnicas, é importante refletir sobre o objetivo a ser alcançado. Esse objetivo vai determinar vários aspectos tais como a quem aplicar e, especialmente, em que momento do trabalho de campo ela deve ser usada.

Ainda em referência à sugestão de intensificação de métodos e técnicas que privilegiem a apreensão de elementos que não são diretamente "visíveis", a apreensão da interconexão de diferentes práticas como meio de ampliar a visão sobre determinada organização social, e de superar as limitações impostas pela linguagem falada e escrita no estudo da prática, metodologias e técnicas que lancem mão dos recursos de captação de imagens e sons são desejáveis, tendo em vista a importância da corporeidade e dos arranjos sociomateriais na apreensão e compreensão das práticas. Para tal, destacamos primeiramente a autoconfrontação cruzada preconizada por Clot (2008).

Para o autor francês, nem sempre o que é importante está na atividade real, ou seja, aquela que é acessível pela simples observação e descrição. Para ele há uma dimensão da atividade humana que necessita de um trabalho adicional do pesquisador para sua apreensão. Clot (2008, p. 103) denomina essa dimensão de "real da atividade", e a descreve como sendo composta também por "o que não se faz, o que se tenta fazer sem ser bem-sucedido,..., o que se desejaria ou poderia ter feito e o que se pensa ser capaz de fazer noutro lugar.... q que se faz para evitar fazer o que deve ser feito; o que deve ser refeito, assim como o que se tinha feito a contragosto". Para essa apreensão ele propõe a autoconfrontação 
cruzada, que por ser baseada numa dinâmica de debate e de busca da dimensão coletiva do trabalho, consideramos adequada para o uso em um EBP.

O principal objetivo a ser alcançado é, por meio do desencadeamento de uma análise reflexiva acerca das atividades habituais e cotidianas, transformar o trabalho em um objeto do pensamento. Em termos práticos, a autoconfrontação cruzada é um processo no qual cada sujeito, sobre uma mesma atividade, analisa e comenta a atividade dos outros. 0 registro de som e imagem da atividade de cada um é o material básico sobre os quais se dão os comentários dos diversos sujeito, criando um sujeito coletivo que se forma a partir dessa análise, pois os agentes comprometidos na análise (pesquisador e trabalhadores) ocupam simultaneamente os papéis de observados e observadores, tornando-se coautores dos dados recolhidos, e tendo papel importante na análise dos mesmos (CLOT, 2008).

Há que se considerar que o trabalho de Yves Clot foi elaborado como uma proposição intervencionista que visa ampliar o poder de agir dos sujeitos, por meio da interação dialógica que possibilita o encontro dos sujeitos, não na atividade propriamente, mas em outra: na atividade de análise do processo de trabalho, que possibilita a criação de um novo objeto de pensamento e seu desenvolvimento.

Porém, consideramos que a sua aplicação pode ser muito útil na apreensão e representação de uma prática, pois novas percepções da realidade podem emergir da atividade conversacional. Ao explicitar como o significado das palavras vai se alterando ao longo do diálogo, a atividade conversacional se coloca então a serviço da atividade de análise, possibilitando organização da bifurcação da significação, ou seja, sem que as partes tenham que concordar integralmente podem encontrar pontos de apoio mútuo para o desenvolvimento do próprio pensamento. São esses pontos mútuos que podem contribuir para representar uma prática e compreender o processo de construção de sua inteligibilidade.

Tendo em vista a importância dada à vida cotidiana na nossa proposta de imersão fenomenológica, outras possibilidades se apresentam e devem ser exploradas, graças aos avanços das tecnologias digitais. Quanto mais a vida cotidiana possa ser capturada na situação em que ela ocorre, mais tende a contribuir em um EBP. No entanto essa captura é mais difícil de realizar do que propor. Essa dificuldade se dá em função de fatores tais como: (1) a mudança de comportamento do sujeito quando observado; (2) a atenção do sujeito focada em um objeto não significa o impedimento da percepção e influência de outros elementos de seu entorno; e, por fim, (3) alguns elementos da experiência cotidiana são tácitos, distribuídos no grupo e transitórios (LAHLOU, 2010). Alguns estudos recentes têm buscado superar esses desafios, e são resumidamente apresentados a seguir.

Há uma série de estudos voltados para a captura e transmissão da experiência cotidiana utilizando novas tecnologias digitais. Dentre esses exemplos destacam-se: (1) o uso de um aplicativo para telefone celular que é um híbrido de blog, rede social e canal de vídeo, e permite o compartilhamento em tempo real de pensamentos e descrições de ações, com o objetivo de apreender a construção coletiva de conteúdo, com base na teoria da atividade (LEWIS; PEA; ROSEN, 2010); (2) o uso de micro-câmeras portáveis para analisar as ações e os gestos de operários em uma fábrica, com o objetivo de transmissão de conhecimentos para novatos (LE BELLU; LAHLOU; NOSULENKO, 2010); (3) um estudo etnográfico utilizando uma micro-câmera portável e um software de edição colaborativa de textos, focado em atividades realizadas no ambiente doméstico (CORDELOIS, 2010); (4) 
uma tentativa da Agência Nacional de Pesquisa da França em construir um arquivo digital na esfera científica baseado em spoken-data, ou seja, diálogos e monólogos analisados por métodos linguísticos (HABERT; HUC, 2010); e, por fim, (5) o uso de ambientes colaborativos para o compartilhamento de práticas de pesquisa, de ensino e de elaboração de conteúdos, com a possibilidade de capturar elementos objetivos e subjetivos envolvidos nessas experiências (KANE; FICHMAN, 2009).

Para Lahlou (2010), o uso de tecnologia digital para os estudos focados na experiência traz algumas contribuições para superar as dificuldades de abordagem dessa categoria de análise. Uma delas é a capacidade desses meios tecnológicos de permitir que a experiência, multimodal e situada, possa ser revivida do ponto de vista do sujeito, permitindo sua gravação "subjetiva". O uso de mecanismos portáveis que retratam o ponto de vista do sujeito, tornando-o seu próprio observador, têm essa função.

Essa auto-observação contribui para superar outro desafio da captura da experiência, qual seja, a redução do efeito do observador no comportamento de quem é observado. Por fim, a possibilidade de rever a experiência do mesmo ponto de vista ajuda a rememorar e reviver os detalhes objetivos e subjetivos presentes naquele momento.

É verdade que, apesar dessas contribuições, essas ferramentas colocam novos problemas: ao utilizar essa câmera o sujeito acaba por interferir na percepção que os outros que com ele agem e interagem têm da situação, mudando os comportamentos deles e, por conseguinte, a situação como um todo. Mesmo assim, consideramos importante a reflexão sobre sua utilização, porque assim como a autoconfrontação cruzada apresentada acima, há potencial para a importante contribuição de se acessar possíveis breakdowns.

Os métodos e técnicas sugeridos apontam para um campo fértil de possibilidades na abordagem da prática. Se o pressuposto defendido nesse artigo está correto, essa abertura de novas possibilidades de estudo é também uma abertura para a ampliação da capacidade de apreensão e representação da prática, por meio da ampliação da imersão do pesquisador que é necessária, mas não suficiente. Acreditamos que essa ampliação deve aumentar 0 poder de explicação da realidade pela teoria, mediante o enfrentamento dos limites de uma abordagem meramente descritiva de uma prática.

Alguns campos de estudo podem se beneficiar significativamente dessa abordagem, em especial aqueles que focalizam fenômenos onde predominam a intersubjetividade, as relações sociais e a interconexão de práticas tais como estudos sobre poder, agência, aprendizagem organizacional com destaque para a aprendizagem de grupo, entre outros.

\section{CONCLUSÃO}

A revisão de periódicos europeus mostrou que os EBP na Europa se fortaleceram na medida em que caminharam em dois sentidos: busca de construção de teorias capazes de uma abordagem crítica da realidade, e construção de diversidade conceitual e metodológica. Longe de querer reproduzir os passos dados pelos pesquisadores europeus, o presente artigo partiu dessa constatação para discutir uma possibilidade teórico-metodológica para a pesquisa no Brasil, proposta essa que ainda carece de uma discussão que ressalte as particularidades do campo, mais especificamente as peculiaridades das organizações brasileiras. 
A imersão proposta no artigo se justifica se tomada a partir de uma visão da prática de base fenomenológica, não-representacional e não-proposicional, na qual a construção e reconstrução da inteligibilidade pelos praticantes se confunde com a própria construção e reconstrução da prática. Além disso, tomada concomitantemente como conteúdo, processo e produto das atividades humanas coletivamente organizadas, ela é a unidade básica de análise do social, e seu estudo aprofundado permite focalizar o processo de construção e sobrevivência coletiva de uma organização.

Nesse sentido, a imersão fenomenológica busca enfrentar os desafios para pesquisas dessa natureza, já apresentados anteriormente, que aqui buscamos resgatar e apontar os principais benefícios dessa abordagem teórico-metodológica. Em primeiro lugar a imersão fenomenológica e etnográfica permite uma abordagem de sucessivas aproximações com 0 objeto estudado, com a ampliação da capacidade do pesquisador em perceber nuances e elementos cuja delimitação não é possível de forma totalmente objetiva. Dentre esses elementos destacamos os "não-ditos" e os "não-feitos" que compõem a inteligibilidade compartilhada pelos praticantes, mas que não se manifestam necessariamente em ações objetivas. Na medida em que o pesquisador vai além da condição de observador e se aproxima ele próprio da condição de praticante, amplia a capacidade de perceber esses elementos, e compreender de que forma eles participam da prática e da organização social estudada.

Outro aspecto importante é que o caráter situado da prática estudada, bem como o papel que a interconexão com outras práticas tem na sua própria constituição e na constituição da organização social, somente esse grau elevado de envolvimento do pesquisador com o universo pesquisado permite compreender esses arranjos de práticas, que se vistos de fora se constituem apenas em ações e atividades que têm algum grau de relação entre si.

As interconexões e os elementos não objetivos que constituem uma prática não podem ser expressos integralmente pela linguagem oral e escrita, mas essa limitação pode ser enfrentada pelo pesquisador ao trazer à tona, e transformar em objeto epistêmico, alguns aspectos importantes. Somente a participação ativa do pesquisador pode propiciar experiências capazes de colocá-lo diante do papel que a corporeidade, os arranjos sociomateriais, e os elementos éticos e estéticos têm na constituição, reprodução e reconstrução da prática e da organização social estudada.

A discussão e as proposições postas neste artigo adotaram como desafio, dentro dos EBP, alcançar a construção da inteligibilidade de uma prática, considerando que esse objeto de análise está em construção constante, é dinâmico e muitas vezes fugidio, não havendo a constituição de uma única inteligibilidade, senão de forma temporária. A participação do pesquisador de forma imersa e profunda em uma prática permite que ele próprio passe a ser um sujeito ativo nesse processo. Estudar a inteligibilidade de uma prática é estudar sua construção, reprodução e reconstrução, mas também é estudar o processo de transformação dessa prática em um objeto epistêmico, o que requer a compreensão do processo de construção, reprodução e reconstrução da inteligibilidade da própria prática de pesquisa.

Embora este artigo não traga resultados de um trabalho teórico empírico, espera-se que essa limitação seja compensada pela discussão empreendida. Pois, ela procura valorizar a investigação da diversidade teórica e metodológica, de forma a permitir que a 
pesquisa lide com o que emerge em campo, dialogando com as bases por ela adotadas até então, aceitando mudanças monitoradas sem perda dos critérios de qualidade, tais como o rigor. Mais especificamente, a imersão fenomenológica, em uma perspectiva de prática não representacional, levanta a hipótese de que, na abordagem dos EBP, ela possa contribuir para explorarmos a noção de aproximação epistêmica, laborando assim nos estudos das atividades processuais, relacionais e negociáveis, dos fenômenos sociais, com os construtos que são considerados referenciais, tais como identificação, familiaridade e estranhamento, reflexividade, multiplicidade.

Além disso, o artigo procurou oferecer uma modesta contribuição como ensaio reflexivo - ao apresentar e resumir analiticamente importantes autores das áreas - em EPB e metodologia em EPB, do Brasil e do exterior -; no caso, com a revisão bibliográfica junto a seis edições especiais de periódicos europeus e de autores e pesquisadores brasileiros, cotados entre os mais importantes na área em nosso país; e também procurou contribuir como ensaio argumentativo - ao apresentar proposições com base no diálogo argumentativo com as ideias desses autores. No caso, trazer e discutir ideias que pretendem ampliar os recursos metodológico e analíticos tais como a entrevista com o sósia, a autoconfrontação cruzada, e os meios digitais e suas implicações.

Com a discussão empreendida nesse artigo buscamos contribuir com a ampliação e o aprofundamento teórico e metodológico dos estudos organizacionais baseados nas teorias da prática. A nosso ver, a imersão fenomenológica proposta aumenta a capacidade do pesquisador em capturar e compreender aspectos dos fenômenos organizacionais que não são acessíveis pela simples observação. Entendemos que o caráter teleológico de construção de uma prática, e o caráter coletivo e compartilhado da construção da inteligibilidade dessa prática, são caminhos para a ampliação do conhecimento do processo de construção, manutenção e reconstrução de uma organização como um conjunto de práticas interconectadas, não apenas nos seus aspectos formais e explícitos, mas especificamente em seus aspectos subjetivos e simbólicos, colocando luz sobre temas como mudança organizacional e poder, entre outros.

Ademais, esperamos que essa perspectiva metodológica e de análise, também possa contribuir para os estudos sobre os processos constitutivos da agência e das identidades, individuais e coletivas. E, com essa lente focada sobre a dinâmica do cotidiano no trabalho e em organizações, explorar a mutualidade desses processos com a manutenção e mudança das condições estruturantes, e, em especial, com a emergência da constituição sociomaterial.

Acreditamos que a discussão possa concorrer para se investigar novos ângulos da aprendizagem no ambiente de trabalho ao incluir no quadro conceitual de análise a reflexividade - representada, por exemplo, nos atos de reflexão e nos atos de argumentação, ambos intersubjetivos -, como componente do knowing-in-use e dos arranjos decisórios e políticos. E ainda na possibilidade de descrever e explorar a mediação moral das racionalidades e das inteligibilidades concorrentes na mesma sociomaterialidade e prática. Por fim, recomendamos que estudos futuros focalizem a proposição de uma agenda de pesquisas nos diversos campos dos estudos organizacionais que sejam compatíveis com a proposta. 


\section{REFERÊNCIAS}

AMÉRICO, B. L.; TAKAHASHI, A. R. W. Conhecimento, aprendizagem organizacional e poder na rede: um estudo de caso na Secretaria de Educação e Cultura de Coahuila, México. Revista de Administração Pública, v. 48, n. 2, p. 411-438, 2014.

ANGROSINO, M. Doing Ethnographic and observational research. SAGE, 2008.

BARLEY, S.; KUNDA, G. Bringing work back in. Organization Science, v. 12, n. 1, p.76-95, 2001.

BATE, S. P. Whatever happened to organizational anthropology? A review of the field of organizational ethnography and anthropological studies. Human Relations, v. 50, n. 9, p. 1147-1175, 1997. doi:10.1023/A:1016961918626.

BISPO, M. S. Estudos baseados em prática: conceitos, história e perspectivas. In: DAVEL, E. P. B. (ed.). Revista Interdisciplinar de Gestão Social - edição especial sobre Práticas. Universidade Federal da Bahia, Escola de Administração, Centro Interdisciplinar de Desenvolvimento e Gestão Social, v. 2, n. 1, 2013.

. Methodological Reflections on Practice-Based Research in Organization Studies. BAR - Brazilian Administration Review, v. 12, n. 3, p. 309-323, 2015a. doi:10.1590/ 1807-7692bar2015150026.

E-learning as organizing practice in higher education. In KENNEDY, M. et al. (eds.). Practice-based learning in higher education: jostling cultures. Netherlands: Springer International, 2015b, p. 11-126.

. Tourism as practice. Annals of Tourism Research, n. 61, p. 170-179, 2016. doi: 10.1016/j.annals.2016.10.09.

BISPO, M. S.; GODOY, A. S. Etnometodologia: uma proposta para pesquisa em estudos organizacionais. Revista de Administração da UNIMEP, v. 12, n.2, 108-135, 2014, maio-agosto. doi: 10.15600/1679-5350/rau.v12n2p108-135.

BJøRKENG, K.; CLEGG, S.; PITSIS, T. Becoming (a) Practice. Management Learning, v. 40, n. 2, p. 145-159, 2009.

BROWNLIE, D. et al. Management theory and practice: bridging the gap through multidisciplinary lenses. European Business Review, v. 20, n. 6, p. 461-470, 2008. doi: 10.1108/09555340810913494.

CILLIERS, P. Why We Cannot Know Complex Things Completely. Emergence, v. 4, n. 1/2, p. 77-84, 2002.

CASSANDRE, M. P. et al. Gênero e Estilo na Prática das Manipuladoras de Alimentos: uma aproximação empírica aos estudos organizacionais na perspectiva sócio-histórica e cultural. In: XXXIV EnANPAD, Rio de Janeiro. Anais Eletrônicos, 2010.

CLOT, Y. La fonction psychologique du travail, $5^{\mathrm{a}}$ ed, Paris: PUF, 1999.

Travail et pouvoir d'agir. Paris: PUF, 2008. 
CORDELOIS, A. Using Digital Technology for Collective ethnographic observation: an experiment on "coming home". Social Science Information, v. 49, n. 3, p. 445-463, 2010.

DALL'ALBA, G.; SANDBERG, J. A Phenomenological Perspective on Researching Work and Learning. In: BILLET, S. et. al. (eds.). International Handbook of Research in Professional and Practice-based Learning. Springer Science, 2014.

DREYFUS, $\mathrm{H}$. Detachment, involvement, and rationality: are we essentially rational animals? Human Affairs, n. 17, p. 101-109, 2007. doi: 10.2478/v 10023-007-0010-0.

EIKELAND, O.; NICOLINI, D. Turning practically: broadening the horizon. Journal of Organizational Change Management, v. 24, n. 2, p. 164-174, 2011. doi: 10.11.08/09534811111119744.

FARIA, A. M.; LEITE-DA-SILVA, A. R. Quando a estratégia como prática encontra com a política pública de turismo: o contexto de um sindicato e de empresas associadas do turismo gastronômico no Espírito Santo. Teoria e Prática em Administração, v. 5, n. 2, p. 72-100, 2015.

FENDT, J.; KAMINSKA-LABBÉ, R.; SACHS, W. M. Producing and socializing relevant management knowledge: re-turn to pragmatism. European Business Review, v. 20, n. 6, p. 471-491, 2008.

GHERARDI, S. Introduction: The Critical Power of the Practice Lens. Management Learning. v. 40, n. 2, p. 115-128, 2009a. doi: 10.1177/1350507608101225.

GHERARDI, S. Knowing and Learning in Practice-based Studies: an introduction. The Learning Organization. v. 16, n. 5, p. 352-359, 2009b. doi: 10.1108/09696470910974144.

GHERARDI, S. Practice? It's a matter of taste! Management Learning. v. 40, n. 5, p. 535550, 2009c. doi: 10.1177/1350 507609340812.

GHERARDI, S. How to Conduct a Practice-based Study: problems and methods. UK/USA: Edward Elgard Publishing Limited, 2012.

GRIX, J. Introducing Students to the Generic Terminology of Social Research. Politics, v. 22, n. 3, p. 175-186, 2002.

HABERT, B.; HUC, C. Building Together Digital Archives for research in Social Sciences and Humanities. Social Science Information, v. 49, n. 3, p. 415-443, 2010.

HEIDEGGER, M. Being and Time: a revised edition from Stambaugh translation. Albany: State University of New York Press, 2010.

HOLBROOK, M. B. Compromise is so... compromised: Goldilocks, go home. European Business Review, v. 20, n. 6, p. 570-578, 2008.

IEDEMA, R.; CARROL, K. The "clinalyst". Journal of Organizational Change Management, v. 24, n. 2, p. 175-190, 2011.

IPIRANGA, A. S. R.; LOPES, L. L. S.; SOUZA, E. M. A experiência estética nas práticas culinárias de uma organização gastronômica. Organizações \& Sociedade, Salvador, v. 23, n. 77, p. 191-210, abr./jun. 2016. 
JÚLIO, A. C. Produzindo o Desfile Carnavalesco de uma Escola de Samba: Contribuições de Theodore Schatzki. In: EnAnpad 2015 - XXXIX Encontro da ANPAD. Belo Horizonte. Anais Eletrônicos, 2015.

JÚLIO, A. C.; BIANCO, M. F. Aprendizagem como prática social e o contexto da sociedade pós-industrial. In: II CBEO - Congresso Brasileiro de Estudos Organizacionais. Uberlândia MG. Anais Eletrônicos, 2014.

JÚLIO, A. C.; TURETA, C. Estratégia como Prática na Produção do Desfile de uma Escola de Samba. In: VII Encontro de Estudos em Estratégia. Anpad. Brasília/DF. Anais Eletrônicos, 2015.

KANE, G. C.; FICHMAN, R. G. The Shoemaker's Children: using wikis for information systems teaching, research and publication. MIS Quarterly, v. 33, n. 1, p 1-17, 2009.

KOSTULSKI, K. Development of Activity through reflection: the case of the public prosecutor's lapsus linguae. Journal of Organizational Change Management, v. 24, n. 2, p. 191- 210, 2011.

KUHN, T. S. A estrutura das revoluções científicas. 2. ed. São Paulo: Perspectiva, 1978.

LABATUT, J. et al. The active role of instruments in articulating knowing and knowledge - the case of animal qualification practices in breeding organisations. The Learning Organization, v. 16, n. 5, p. 371-385, 2009. doi: 10.1108/09696470910974162.

LAHLOU, S. Digitization and transmission of human experience. Social Science Information, v. 49, n. 3, p. 291-327, 2010. doi: 10.1177/0539018410372020

LE BELLU, S.; LAHLOU, S.; NOSULENKO, V. Capter et transferer le savoir incorporé dans um geste professionnel. Social Science Information, v. 49, n. 3, p. 371-413, 2010.

LEMOS, L.; ALCADIPANI, R. Por uma Epistemologia das Práticas Organizacionais: a contribuição de Theodore Schatzki. Organizações \& Sociedade, v. 22, p 79-98, jan./mar., 2015.

LEWIS, S.; PEA, R.; ROSEN, J. Beyond Participation to Co-creation of Meaning: mobile social media in generative learning communities. Social Science Information, v. 49, n. 3. p. 1-19, 2010.

LÔBO, P. R. O Processo Organizativo da Prática da Greve pelos Bibliotecários de uma Biblioteca Universitária Brasileira. In: III CBEO - Congresso Brasileiro de Estudos Organizacionais. Vitória - ES. Anais Eletrônicos, 2015.

MANIDIS, M. Practising knowing at work: a case study in healthcare. Teoria e Prática em Administração, v. 5, n. 2, p. 27-50, 2015.

MIETTINEN, R.; SAMRA-FREDERICKS, D.; YANOW, D. Return to Practice: an introductory essay. Organization Studies, v. 30, n. 12, p. 1309-1327, 2009. doi: 10.1177/0170840609349860.

NICOLINI, D.; GHERARDI, S.; YANOW, D. Introduction: Toward a practice-based view of knowing and learning in organizations. In: NICOLINI. D.; GHERARDI, S.; YANOW, D. Knowing in organizations: a practice-based approach. M. E. SHARPE, 2003.

NICOLINI, D. Articulating Practice through the Interview to the Double. Management Learning, v. 40, n. 2, p. 195-212, 2009a. doi: 10.1177/1350507608101230. 
NICOLINI, D. Zooming in and out; Studying practices by switching theoretical lenses and trailing connections. Organization Studies, v. 30, n. 12, p. 1391-1418, 2009b. doi: 10.1177/0170840609349875.

. Zooming in and out; a package of method and theory to study work practices. In: $\overline{Y B E M}$ A, S. et al. (eds.). Organizational Ethnography: studying the complexities of everyday life. SAGE, 2009c.

2013

Practice, Theory, Work and organization - an introduction. Oxford University Press,

After practice. Conferência proferida na Summer School on Practice-based studies. Warwick Business School, 2014.

PATRIOTTA, G. Organizational Knowledge in the Making: How Firms Create, Use, and Institutionalize Knowledge. Oxford University Press, 2003.

PIMENTEL, R.; NOGUEIRA, E. E. S. Possibilidades metodológicas para a apreensão da interconexão entre as práticas: a entrevista com o sósia. In: III CBEO - Congresso Brasileiro de Estudos Organizacionais. Vitória - ES. Anais Eletrônicos, 2015.

POUBEL, L.; JUNQUILHO, G. S. A organização das práticas na gestão das escolas públicas brasileiras: uma alternativa de estudo para o contexto escolar. Revista Pensamento e Realidade, v. 30, n. 3, 2015.

PRUS, R. Symbolic Interaction and Ethnographic Research - Intersubjectivity and the study of human lived experience. New York: State University of New York Press, 1996.

QUEROL, M. A. P.; JACKSON FILHO, J. M.; CASSANDRE, M. P. Change Laboratory: uma proposta metodológica para pesquisa e desenvolvimento da aprendizagem organizacional. Administração: Ensino e Pesquisa (RAEP), v. 12, p. 609, 2011.

SANDBERG, J.; TSOUKAS, H. Grasping the logic of practice: Theorizing through practical rationality. Academy of Management Review, v. 36, n. 2, p. 338-360, 2011.

SCHATZKI, T. R. Social Practices: a wittgensteinian approach to human activity and the social. Cambridge University Press: Cambridge, 1996.

The Site of the Social: a philosophical exploration of the constitution of social life and change. University Park, PA: Pennsylvania State University Press, 2002.

. Introduction. Human Affairs, v. 17, n. 12, p. 97-100, 2007. doi: 10.2478/v10023007-0009-6.

. A Primer on Practices. In: HIGGS, J. et al. (eds.). Practice-Based Education: Perspectives and Strategies. Sense Publishers, 2012.

SILVEIRA, P. R. S.; DOIN, T. A. F. Estudo das práticas na ação estratégica de uma escola de samba na passagem do enredo para samba enredo. Revista Facev, n.14, p.130-150, 2015.

SIMONSEN, K. Practice, spatiality and embodied emotions: as outline of a geography of pratice. Human Affairs, v. 17, n. 12, p. 168-181, 2007. doi: 10.2478/v 10023-007-0015-8. 
SOARES, L. C.; BISPO, M. S. Contribuições da estética organizacional para a pesquisa em organizações gastronômicas. Revista Brasileira de Pesquisa em Turismo, v. 8, n. 3, p. 476-493, 2014.

SVABO, C. Materiality in a practice-based approach. The Learning Organization, v. 16, n. 5, p. 360-370, 2009. doi: 10.1108/09696470910974153.

TURNER, S. Practice then and now. Human Affairs, v. 17, n. 12, p. 111-125, 2007. doi: 10.2478/v 10023-007-0011-z.

YBEMA, S. et al. Studying everyday organizational life. In: YBEMA, S. et al. (eds.). Organizational Ethnography: studying the complexities of everyday life. SAGE, 2009.

WITTGENSTEIN, L. Philosophical investigations. Trad. G. E. M Ascombe, P. M. S. Hacker, J. Schulte. United Kingdon: Wiley-Blackwel, 4th ed., 2009.

Data de submissão: 15/06/2016.

Data de aprovação: 09/12/2016. 